\title{
Variability of atmospheric freezing-level height and its impact on the cryosphere in China
}

\author{
Yinsheng ZHANG, ${ }^{1}$ Y. GUO ${ }^{2}$ \\ ${ }^{1}$ Key Laboratory of Tibetan Environment Changes and Land Surface Processes (TEL), Institute of Tibetan Plateau Research, \\ Chinese Academy of Sciences, 18 Shuangqing Road, Beijing 100085, China \\ E-mail: yszhang@itpcas.ac.cn \\ ${ }^{2}$ National Climate Center, China Meteorological Administration, 46 Zhongguancun Nandajie, Haidian District, \\ Beijing 100081, China
}

\begin{abstract}
We used atmospheric air-temperature data from the Chinese radiosonde network to analyze changes in freezing-level heights (FLHs) during the past 48 years and studied their impacts on the cryosphere. We examined radiosonde time-series data from 92 selected Chinese radiosonde network stations. Generally, FLH exhibited a latitudinal zone, declining from the south. The FLH trend during 1958-2005 showed spatial inhomogeneity, most uniform distributions during autumn, and significant upward trends. Temporal variability of FLH in eastern China was briefly associated with El Niño Southern Oscillation events, but the causes of FLH changes in western China require further investigation. FLH in western and northern China has mostly increased since 1958, and might be considered a possible indicator of cryospheric change during the second half of the 20th century. There were significant correlations between FLH and changes in snow cover, glaciers and permafrost.
\end{abstract}

\section{INTRODUCTION}

The rapid retreat of mountain cryospheric components around the world during the 20th century (e.g. glaciers and ice caps) has been cited as proxy evidence of global warming of surface air temperatures (Folland and others, 2001). During the past 50 years, while the cryosphere in China has retreated (Li and others, 2003, 2008), surface airtemperature data show marked upward trends (Tang and Ren, 2005). However, there are few recorded climatic data in extremely cold regions, where cryospheric components are found. This is a barrier to climatological and hydrological investigations in the cryosphere.

The freezing-level height ( $\mathrm{FLH}$; the free-air $0^{\circ} \mathrm{C}$ isotherm) in the atmosphere is a critical parameter that affects hydrological conditions in high mountains (Harris and others, 2000; Hoffmann, 2003; Francou and others, 2004; Coudrain and others, 2005; Vuille and others, 2008). In particular, the mass balance of glaciers is critically dependent on the extent of ice melting and sublimation, and on the balance of snowfall versus rain, which greatly affects albedo and thus net radiation. Diaz and Graham (1996) found that there had been a significant rise in FLHs in the tropics during the period 1958-90, and that this increase was related to sea-surface temperatures (SSTs) in the eastern equatorial Pacific. In the American sector of the tropics, the strongest relationship between FLH and SST occurs when SST precedes FLH by $\sim 3$ months (Diaz and others, 2003). Other high mountain regions have also exhibited significant warming in the last several decades, with more recent decades displaying the largest FLH changes (Diaz and others, 2003).

Turning to free-atmospheric trends and focusing on the tropical belt, Diaz and Graham (1996) examined data from 65 radiosonde stations and found a temporal increase in free-atmospheric FLHs during 1970-86 and, in a ten-station South American network, during 1958-90. These freezinglevel changes were corroborated by surface temperature data from tropical stations at elevations above $1000 \mathrm{~m}$. They were also well simulated by an atmospheric general circulation model, driven by observed SSTs. Using a more comprehensive radiosonde station network, Gaffen and others (2000) noted that tropical FLHs abruptly increased in 1976-77 and slightly decreased during 1979-97. During 1979-97, mid-tropospheric temperatures cooled slightly, while surface temperatures increased significantly, in association with an increase in lower-tropospheric lapse rates. Over a longer period, 1960-97, tropical surface and tropospheric temperatures warmed at about the same rate, and freezing levels rose.

To better understand the apparent discrepancies between recent (past 50 years) cryospheric changes and large-scale warming of the lower troposphere in China, we used radiosonde observations to investigate the following questions:

1. What were the seasonal, interannual and multi-decadal patterns of atmospheric freezing levels in China?

2. How were trends in atmospheric freezing levels related to temperature trends?

3. What were the impacts of atmospheric freezing levels on cryosphere?

Here we investigate changes in FLH derived from radiosonde observations in China, and their possible impact on the cryosphere. We compared the climatological features of temperature and freezing levels at 92 radiosonde sites, interannual variability, and trends. We present several examples of FLH impacts on variation in cryospheric components.

\section{DATA AND METHODS}

\subsection{Data preparation}

FLH, theoretically, can be deduced from vertical profiles of temperature and geopotential heights in free air. Generally, three data sources can be used for this type of vertical 


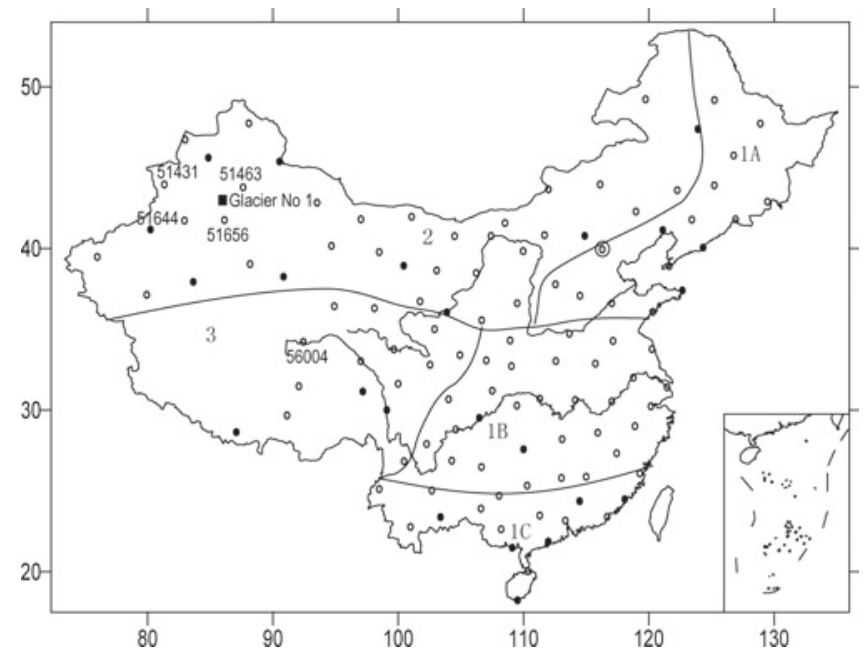

Fig. 1. Location of radiosonde stations In China.

structure analysis in free air: radiosonde, satellite and reanalysis series. However, temperature series from satellite observations can reveal layer-mean values but not individual levels. The reanalysis series is constructed from atmospheric forecasts and data assimilation systems; some authors noted biases from both the US National Centers for Environmental Prediction (NCEP) and European Centre for Medium-Range Weather Forecasts (ECMWF) re-analysis (ERA) models when using it for long-term climatic analysis in China (e.g. Ma and others 2008). Radiosonde data with their vertical resolution, therefore, are more suitable for deducing FLH.

Radiosonde observations, provided by the Chinese $\mathrm{Na}$ tional Meteorological Information Center (NMIC)/China Meteorological Administration (CMA), formed the basis for this analysis. Considering the amplitude of FLH variation, we used data for five mandatory pressure levels: ground surface, 850, 700, 500 and $400 \mathrm{hPa}$, which were observed twice daily at 00 UTC (coordinated universal time) and 12 UTC. The 00 UTC and 12 UTC series were combined into a merged radiosonde time series for the final homogenization procedure; sets of merged series were considered missing if either the 00 UTC or 12 UTC series was missing. Seasonal anomalies were computed with reference to 1971-2000.

The 116 Chinese radiosonde network stations are distributed throughout China (Fig. 1). We examined the data availability for each station and included as many stations as possible. Gaffen and others (2000) demonstrated that the proportion of missing data is a key parameter for determining the reliability of a radiosonde time series. Guo and Ding (2009) found that a $30 \%$ proportion of missing data is the critical value to distinguish the usability of a time series from Chinese radiosonde networks. Thus, based on a maximum fraction of missing data of $30 \%$, we selected an optimal network (Fig. 1, open circles). The analysis yielded a nominal radiosonde time-series network of 92 stations for 1958-2005.

Because of the expansive region and large number of stations, we divided China into five sub-regions according to geographical conditions and atmospheric circulation: regions 1A (northeast China), 1B (east China), 1C (southeast China), 2 (north and west China) and 3 (Tibetan Plateau).

It is well accepted that there is heterogeneity in instrumental climatic records, as well as radiosonde time series; quality control (QC) and homogenization are necessary when using radiosonde data (Solomon and others, 2007). To detect and correct inconsistencies caused by the vagaries of data collection, many statistical methods (e.g. different instruments and data correction methods) have been developed. We employed a hydrostatic method (Collins, 2001) for QC, and a two-phase regression method (Easterling and Peterson, 1995) for data homogenization. These methods have proved suitable for Chinese radiosonde networks (Guo and others, 2008; Guo and Ding, 2009).

Equal-Area Scalable Earth Grid (EASE-Grid) weekly snowcover data were used in this analysis. The Northern Hemisphere 25-km Equal-Area Special Sensor Microwave Imager (SSM/I) Earth (EASE-Grid) Weekly Snow Cover and Sea Ice Extent version 3 database combines extent of snow cover and sea ice at weekly intervals for 23 October 1978 to 5 June 2005 and snow cover alone for 3 October 1966 to 22 October 1978 (R.L. Armstrong and M.J. Brodzik, http:// nsidc.org/data/nsidc-0046.html). Each gridcell contains information indicating the absence or presence of snow cover for each week; this information can be obtained from the website of the US National Snow and Ice Data Center (NSIDC; ftp://sidads.colorado.edu/pub/DATASETS/snow _and_sea_ice/nsidc0046v03). Furthermore, glacier massbalance data and permafrost active layer depths were extracted from reports by Yang and others (2005) and Wu and Zhang (2010), respectively.

\subsection{FLH identification}

The first five levels of radiosonde time series (corresponding to the ground surface, $850,700,500$ and $400 \mathrm{hPa}$ ) were examined for a transition from a temperature greater than $0^{\circ} \mathrm{C}$ to a temperature equal to or less than $0^{\circ} \mathrm{C}$. FLH was estimated for each snapshot by reverse interpolation of the temperature profile at each station to find the geopotential height of the $0^{\circ} \mathrm{C}$ isotherm. The algorithm checks for zero crossings in the temperature profile between ground surface and $400 \mathrm{hPa}$. If a single zero crossing exists, its altitude is taken as the freezing level. Two additional special cases were considered: no zero crossings $\left(T<0^{\circ} \mathrm{C}\right.$ throughout the profile) and multiple zero crossings due to temperature inversions. In the case where $T<0^{\circ} \mathrm{C}$ throughout the column, the freezing level is flagged as missing. In the case of multiple zero crossings, these locations are flagged and only the lowest FLH value is stored. The FLH was then obtained through linear interpolation between the geopotential heights of the transition levels; mean monthly and annual FLH were calculated.

\section{VARIABILITY OF FLH IN CHINA}

Figure 2 shows seasonal distributions of mean FLH during 1958-2005. White areas in all four panels in the figure were caused by absence of stations (cf. Fig. 1). Generally, FLH exhibited latitudinal zone, and declined from south to north. In winter, air temperatures at the ground surface were $<0^{\circ} \mathrm{C}$ over nearly two-thirds of China; FLH averaged $500 \mathrm{~m}$ in mideast China and rose steeply to $4000 \mathrm{~m}$ at the margins of the tropics. FLH in spring and autumn showed similar distributions, with a minimum of $500 \mathrm{~m}$ and a maximum of $5000 \mathrm{~m}$. Spatial variability was minimal in summer, with a range of $<2000$ m.

Figure 3 shows mean seasonal curves of FLH for different regions (Fig. 1) in China. FLH showed steep seasonal variation due to continental climatic conditions. Annual ranges of $\mathrm{FLH}$ averaged $3829 \mathrm{~m}$ in region $1 \mathrm{~A}, 3714 \mathrm{~m}$ in region $1 \mathrm{~B}$ and $1413 \mathrm{~m}$ in region $1 \mathrm{C}$. 

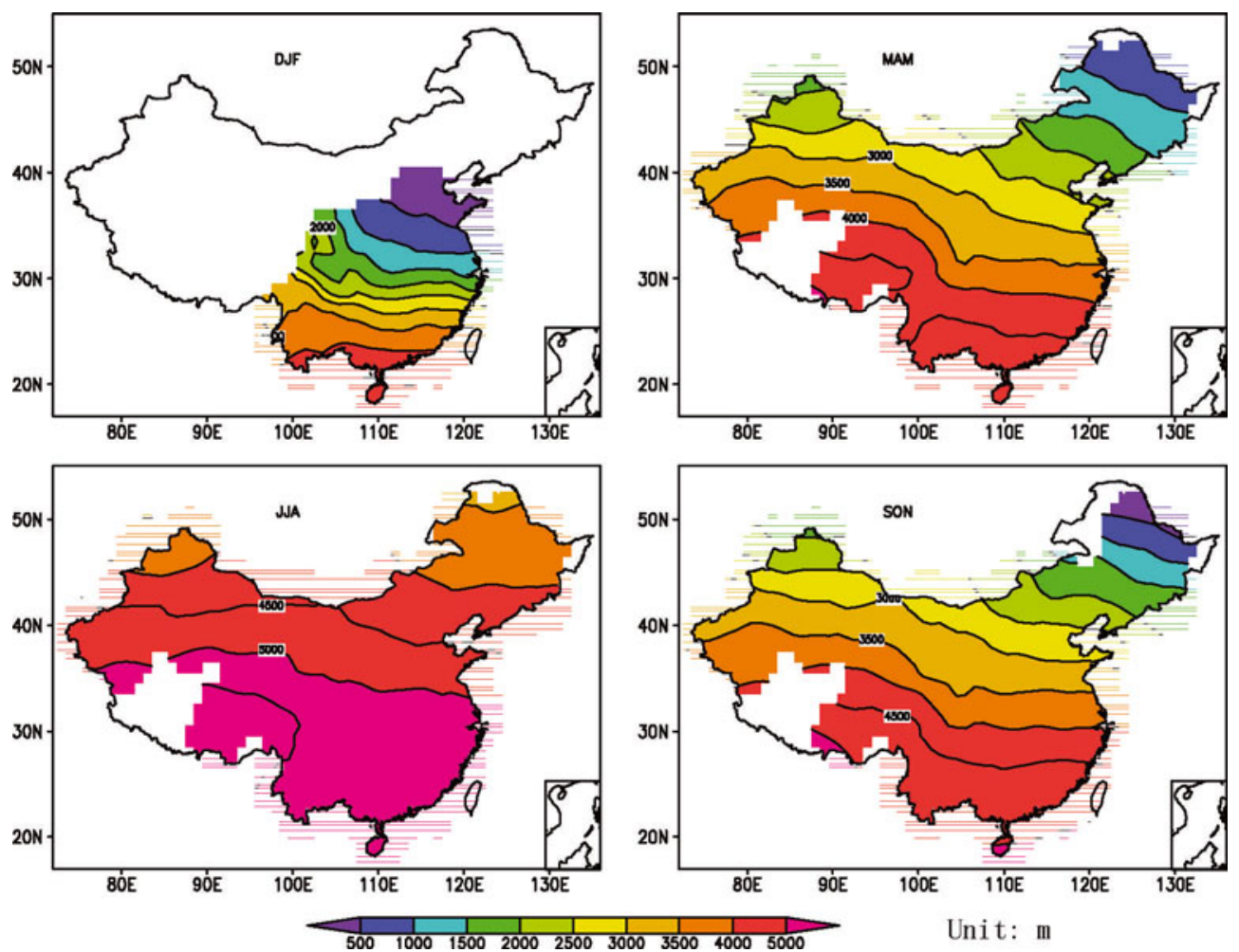

Fig. 2. Mean FLH distribution for different seasons in China during 1958-2005. DJF: December-February; MAM: March-May; JJA: JuneAugust; SON: September-November.

Trends in FLH over the past 48 years (1958-2005) were computed and are shown in Figure 4 (units of $\mathrm{m}(10 \mathrm{a})^{-1}$ ). Winter FLH trends showed overall FLH increases of 0.2 $18 \mathrm{~m}(10 \mathrm{a})^{-1}$ across southeast China. Autumn FLH in most of China increased; extreme positive and negative trends were 11.8 and $3.1 \mathrm{~m}(10 \mathrm{a})^{-1}$, respectively, implying $45 \mathrm{~m}$ increases and $12 \mathrm{~m}$ decreases during 1958-2005. Positive and negative trends of spring FLH were alternately fluctuating in general. FLH in summer, the most important season for cryospheric fluctuations, also fluctuated. However, in both northwest China and the Tibetan Plateau (regions 2 and 3; Fig. 1), the main locations of the cryosphere in China, summer FLH showed predominantly upward trends, consistent with retreat of the cryosphere, including permafrost and glaciers.

To investigate interannual changes in $\mathrm{FLH}$, we summarized decadal mean changes relative to 1971-2000 during

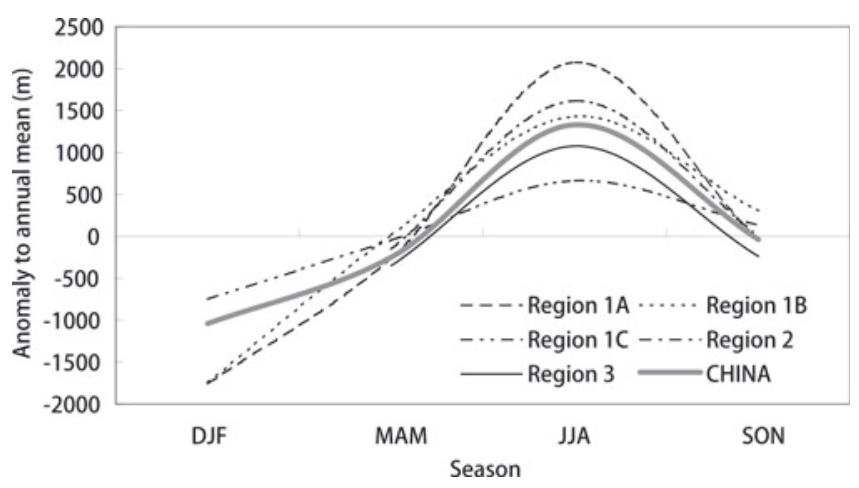

Fig. 3. Seasonal curves of FLH for different regions in China and for all regions. DJF: December-February; MAM: March-May; JJA: June-August; SON: September-November. the decades 1958-67, 1968-77, 1978-87, 1988-97 and 1998-2005 (Table 1). There were decreases in FLH during 1958-67 for all regions. During 1968-97, FLH showed significant upward fluctuations in most regions. On the Tibetan Plateau (region 3), the highest cryospheric region in the world, FLH increased during 1968-77 by $203 \mathrm{~m}$, the sharpest increase during the study period for the entire studied region. In region 2, a typical region of valley glaciers and snow cover, FLH maintained increases over two decades. Region 1A, characterized by permafrost and snow cover, exhibited significant increases of 36 and $60 \mathrm{~m}$ for 1968-77 and 1978-97, respectively. FLH decreased in all regions during 1998-2005, coupled with decreasing air and ground temperatures.

Diaz and Graham (1996) demonstrated that FLHs across the tropics are strongly related to mean tropical SST variations, with the rising SSTs driving freezing levels upward in the atmosphere. El Niño Southern Oscillation (ENSO) variations play a critical role in modulating FLH on an interannual basis across the entire tropical region (Diaz and others, 2003). Considering the importance of ENSO to climatic fluctuation in China, especially eastern China, we plotted the November-March FLH versus ENSO index (Fig. 5); the ENSO index was expressed as the Niño 3 SST anomalies in the central and eastern equatorial Pacific Ocean (Niño 3.5N-5S, 90-150W). FLH in regions $1 \mathrm{~A}$ and $1 \mathrm{~B}$ showed highly significant correlations ( $P$ value) with the ENSO index, where the climatic variation has been shown to be closely related to ENSO. FLH in region 3 (Tibetan Plateau) showed a rather poor correlation with the ENSO index; the climate there has been found to be controlled by a plateau monsoon system ( $\mathrm{Li}$ and others, 2003). FLH in regions $1 \mathrm{C}$ and 2 showed a poor correlation with the ENSO index. The latter is more easily understood: the regional 

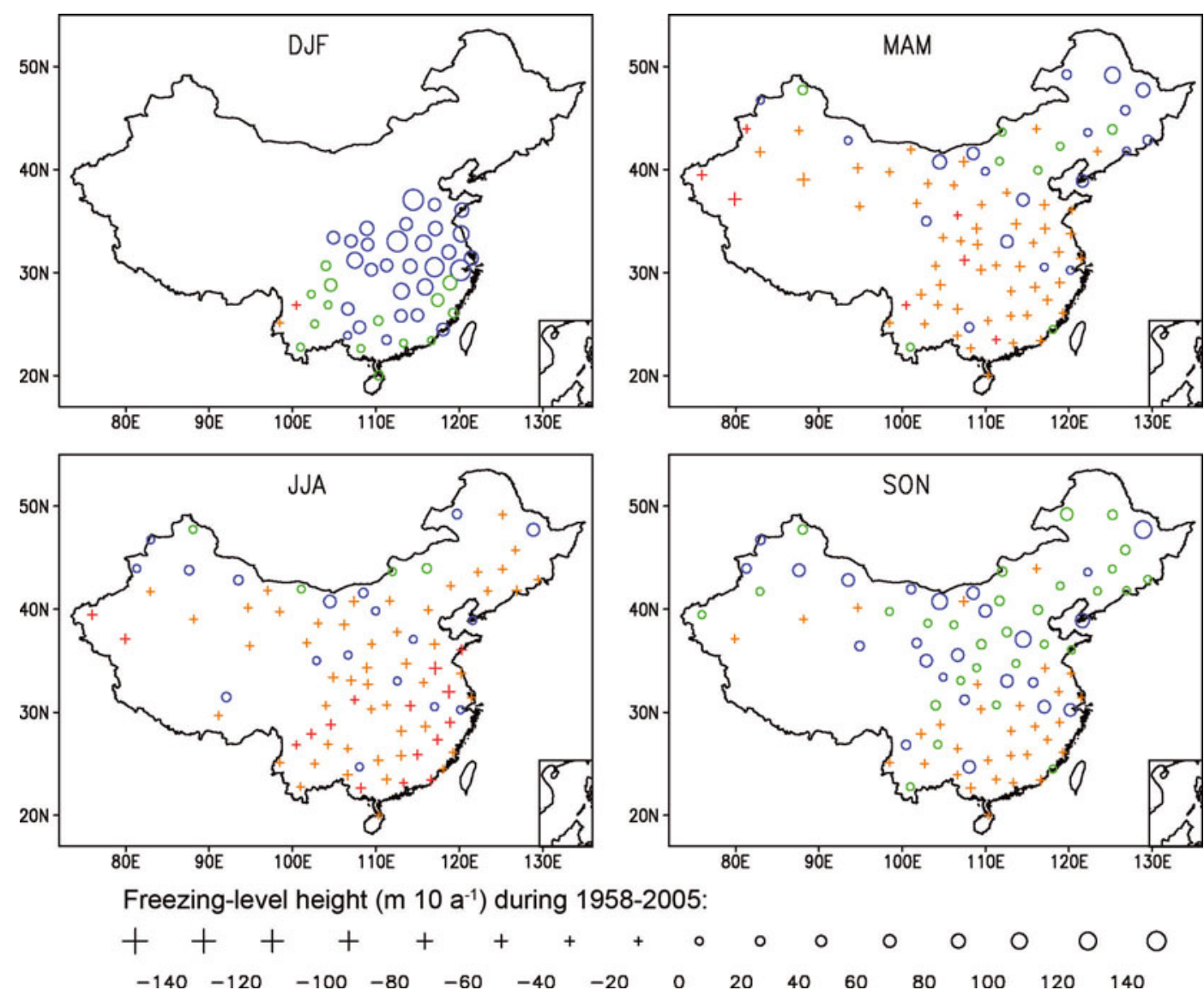

Fig. 4. FLH trends during 1958-2005 at selected stations. DJF: December-February; MAM: March-May; JJA: June-August; SON: SeptemberNovember.

climate is dominated by the western jet stream. The poor correlation in region $1 \mathrm{C}$, however, calls for further investigation, because ENSO events would be predicted to prevail.

\section{IMPACT OF FLH ON CRYOSPHERIC CHANGES}

\subsection{FLH and snow cover}

Snow cover suppresses surface heating by acting as a heat sink, in that energy is transferred to the atmosphere during the melting process and the sensible heat flux is greatly reduced. This, combined with the high surface albedo, will create negative changes in air temperatures in most snowcovered areas, even during the day.

Snow cover for each month was assessed from the NSIDC Equal-Area Scalable Earth (EASE) gridded weekly version 3 dataset (Armstrong and Brodzik, http://nsidc.org/data/nsidc0046.html), which indicates, for each week from 1971 to
2005 , the presence or absence of snow cover on a $25 \mathrm{~km}$ equal-area grid. The relevant grid pixel was identified for each station, and a snow index approximating the percentage of time with snow cover was calculated for each month by assigning 1 to snow-covered weeks and 0 to snowfree weeks, then averaging four or five weekly values. Individual weeks were assigned to the month with the most days in that week (e.g. the week of 29 January-4 February would be assigned to February).

Having checked the variation of snow cover, we found the snow-cover disappearance date was well correlated with the spring FLH in the same area. Figure 6a shows a time series of spring FLH departures from a 1958-2005 reference mean for snow-covered regions, and relative changes in the date of snow-cover disappearance. The negative changes in snow-cover disappearance, indicating an earlier disappearance of snow cover, coincided with increased FLH (Fig. 6b).

Table 1. Decadal mean differences (m) compared to 1971-2000 of FLH for different regions

\begin{tabular}{|c|c|c|c|c|c|c|}
\hline & Region 1A & Region 1B & Region 1C & Region 2 & Region 3 & Mean \\
\hline $1958-67$ & -94 & -56 & -2 & -93 & -29 & -60 \\
\hline $1968-77$ & 36 & 76 & 34 & 49 & 203 & 52 \\
\hline $1978-88$ & 60 & 12 & -14 & 44 & 14 & 23 \\
\hline 1988-97 & -97 & 66 & 36 & -88 & 33 & -19 \\
\hline 1998-2005 & -21 & -46 & -33 & -33 & -22 & -43 \\
\hline
\end{tabular}




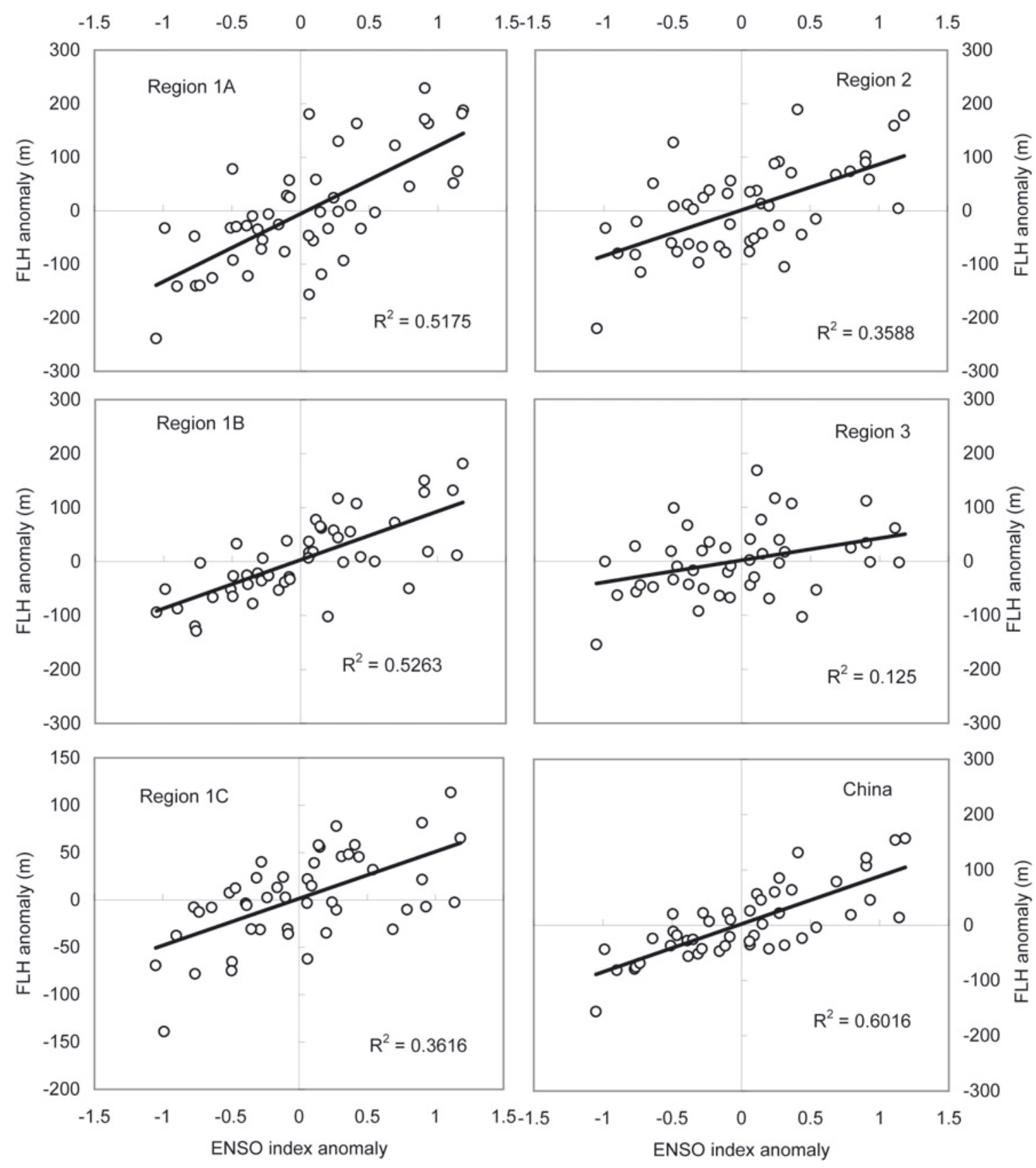

Fig. 5. Variation of FLH during November-March versus ENSO index.
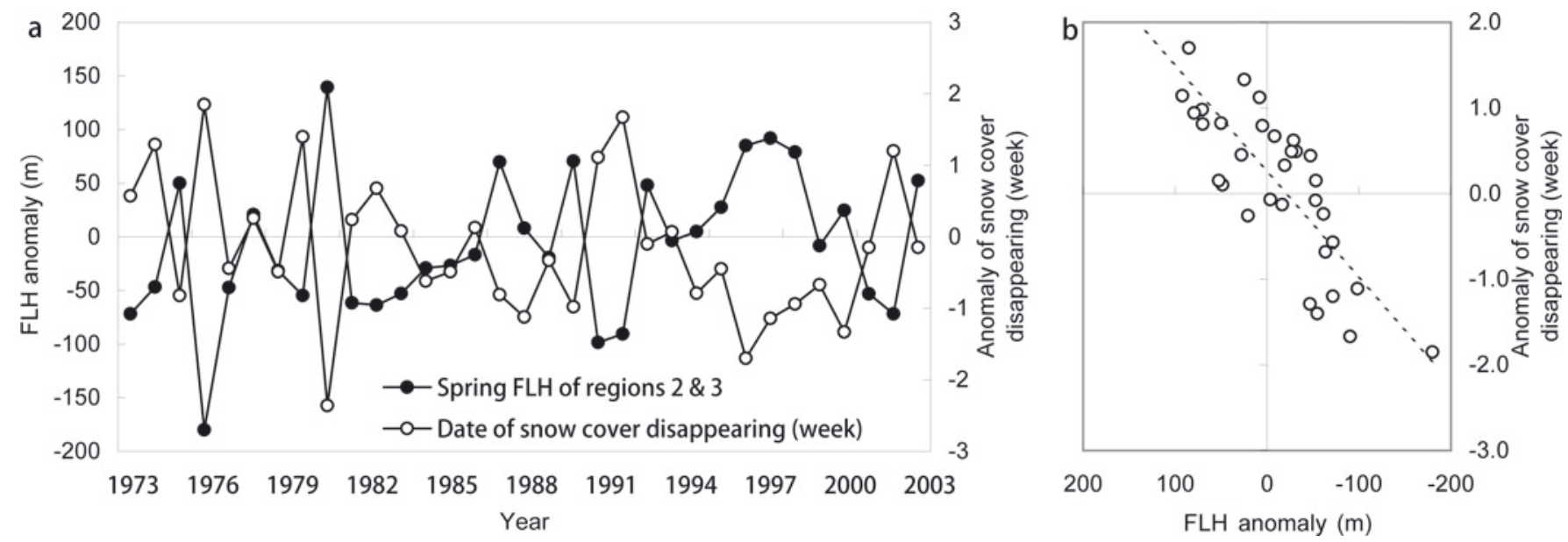

Fig. 6. Variation of snow-cover disappearance date versus relative FLH during spring. (a) Time series and (b) plots of correlation. 

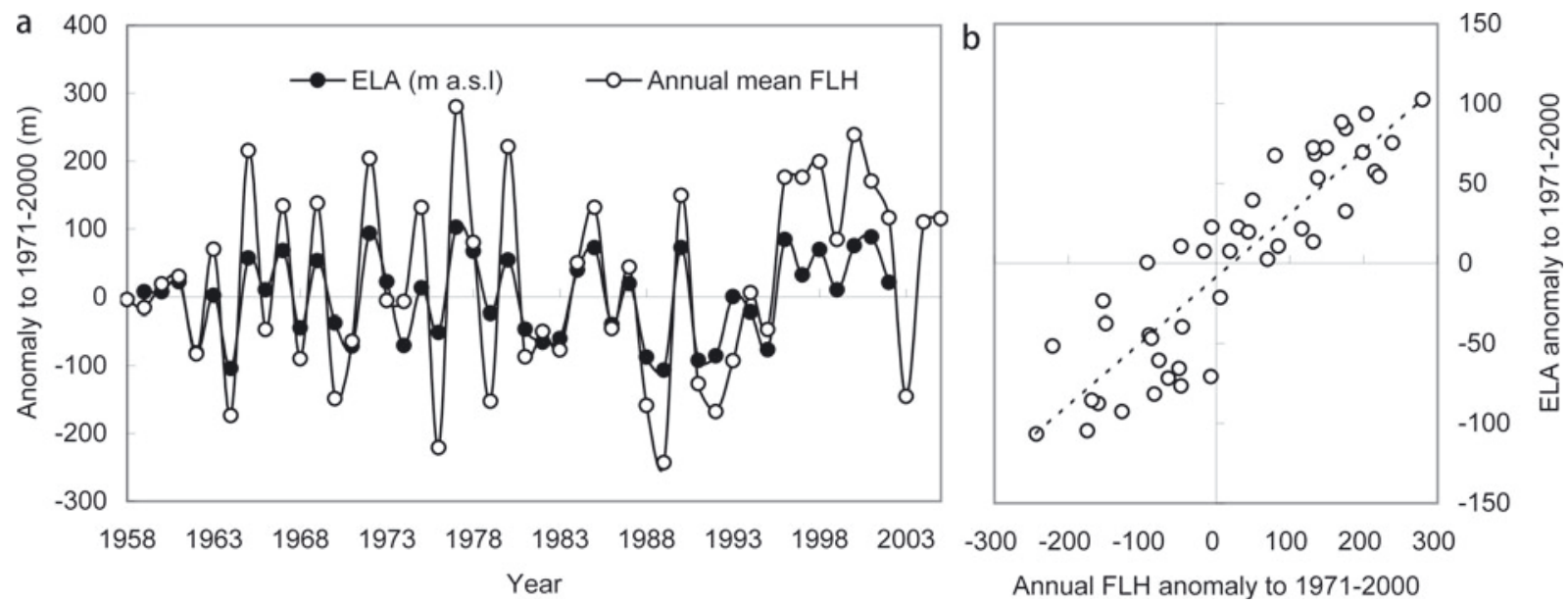

Fig. 7. Variation of ELA on Ürümqi glacier No 1 versus relative FLH. (a) Time series and (b) plots of correlation.

\subsection{FLH and glaciers}

According to the Concise Chinese Glacier Inventory, there are 46377 glaciers in China, covering an area of $59425.18 \mathrm{~km}^{2}$, which represents $51.2 \%$ and $10.9-11.6 \%$ of the mountain glaciated areas in Asia $\left(116.18 \times 10^{3} \mathrm{~km}^{2}\right)$ and on Earth (excluding the glaciers and ice caps surrounding the Greenland and the Antarctic ice sheets; $\left.\left(512 \times 10^{3}\right)-\left(546 \times 10^{3}\right) \mathrm{km}^{2}\right)$, respectively. Recent investigations indicate that glaciated areas in China have shrunk by about $2-10 \%$ over the past 45 years. Total glaciated area has receded by $\sim 5.5 \%$ (Li and others, 2008). Regrettably, because there is no observational network in these high mountains, these changes are occurring without adequate monitoring, yet the consequences of the changes in glacier mass balance will have significant social and economic consequences far downstream, in lowland areas into which the glacier-fed streams and rivers drain (Vergara and others, 2007).

Figure 7 shows an example of the variation of equilibrium-line altitude (ELA) of Ürümqi glacier No 1 versus local FLH; ELA data were obtained from the World Glacier Monitoring Service dataset (WGMS, 2008). The ELA of the glacier has been proven to be more sensitive to air temperatures than to precipitation (Zhang and others, 1998). The local FLH (Fig. 7), averaged from four radiosonde stations near the glacier (shown in Fig. 1 by stations), has exhibited a clear upward trend since the late 1980s. Variation of the ELA of the glacier showed good correlation with FLH (Fig. 7b). From 1980 to 2002, the mass balance of the glacier decreased by $12200 \mathrm{~mm}$ w.e., in conjunction with an FLH increase of $\sim 300 \mathrm{~m}$.

Diaz and others (2003) reported that FLHs across the tropics have risen by $45 \mathrm{~m}$, on average, over the past 30 years. If this same relationship prevailed during glacial times, a mean SST cooling of $2-3^{\circ} \mathrm{C}$ (as most paleoceanographic proxies now suggest) would have led to a fall in the $0^{\circ} \mathrm{C}$ isotherm across the tropics by $500-750 \mathrm{~m}$, with obvious effects on glaciation throughout the mountains of the region. Additional factors, such as an increase in the fraction of precipitation falling as snow (and less as rain) and associated changes in albedo and absorbed solar radiation accompanying the change in FLH, would have reinforced the effects of lower temperatures, leading to more positive massbalance regimes, and increased glaciation of the high mountains (Wagnon and others, 2001; Favier and others, 2004; Vuille and others, 2008).

\subsection{FLH and permafrost}

Wu and Zhang (2010) investigated spatial variations of active layer thickness (ALH) on the Tibetan Plateau. From
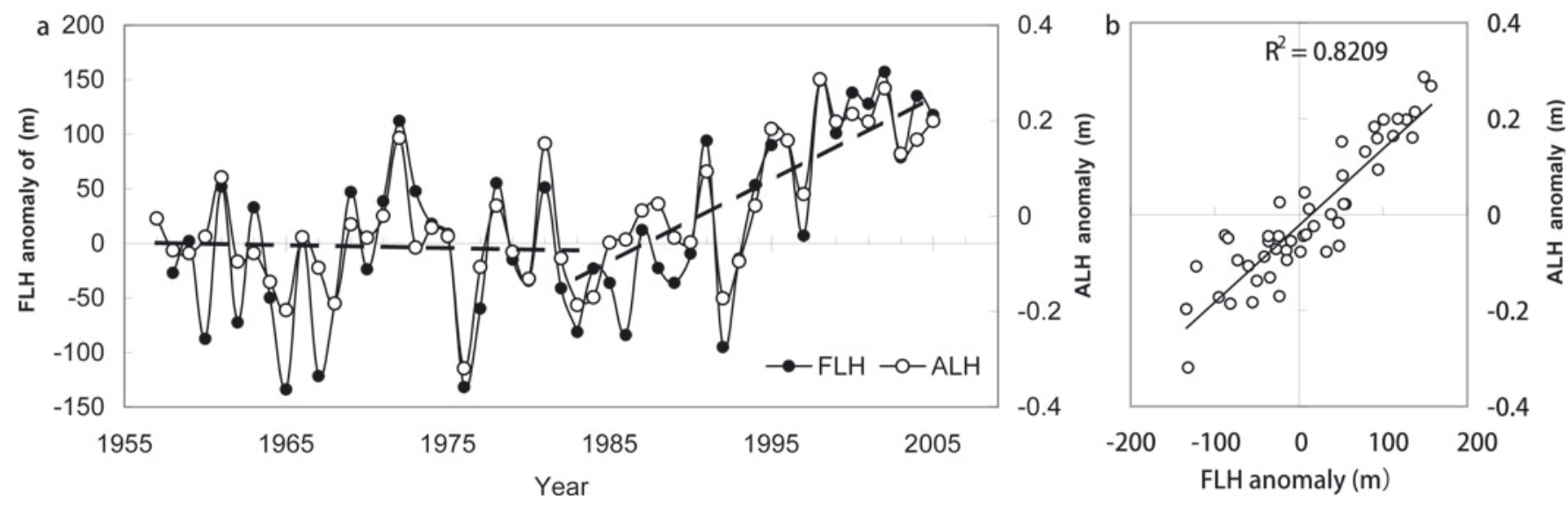

Fig. 8. Variation of ALH at Wudaoliang, Tibetan Plateau, versus relative FLH. 
their work, we provide an example of ALH variation during 1956-2005, that at Wudaoliang station (Fig. 8). ALH showed no or very limited change from 1956 to 1983 and a sharp increase of $\sim 39 \mathrm{~cm}$ from 1983 to 2005 . Figure $8 \mathrm{~b}$ reveals a rather close correlation between ALH and local FLH (56004 in Fig. 1). Figure 8b shows that variation of $\mathrm{ALH}$ and FLH not only corresponded well in trends but were also synchronized in time.

\section{SUMMARY}

The most recent Intergovernmental Panel on Climate Change (IPCC) late-21st-century climate projections (Solomon and others, 2007) show that warming of the atmosphere will be enhanced as greenhouse gases increase. Hydrometeorological observations in recent decades, together with geophysical evidence of melting and rapidly receding mountain glaciers, suggest that high-elevation mountain regions are already experiencing the environmental effects of global warming. Previous works have argued that the potential effects of an amplification of the global warming signal in mountain regions need to receive greater attention from researchers and international funding agencies (Bradley and others, 2004; Diaz and others, 2003). A resumption of warming will result in even more rapid changes in the cryosphere.

The pattern of evolution of the FLH might be considered a possible indicator of global climate change during the second half of the 20th century. In our study, we have demonstrated that the temporal variability of FLH in eastern China is associated with ENSO events, but the causes of alterations in FLH in western China will require advanced investigations. We used atmospheric air-temperature data from the Chinese radiosonde network to analyze changes in FLH during the past 48 years and examined their impact on the cryosphere. We examined radiosonde time series from 92 stations selected from the entire Chinese network. Generally, FLH exhibited a latitudinal zone and declined from south to north, but amplitudes of spatial variation varied in accordance with the seasons. The FLH trend during 1958-2005 showed spatial heterogeneity, most uniform distribution in autumn, and significant upward trends. Temporal variability of FLH in eastern China was briefly associated with ENSO events, but the cause of FLH changes in western China calls for advanced investigation. FLH in western and northern China has generally increased since 1958 and might be considered a possible indicator of global climate change in the second half of the 20th century. There were significant correlations between FLH and changes in snow cover, glacier and permafrost.

\section{ACKNOWLEDGEMENTS}

This study was funded by the Major State Basic Research Development Program of China (973 Program) under grant Nos. 2010 CB951701 and 2010CB428606 and by the Natural Science Foundation of China (No. 59540775045 and No. 41071042), also supported by the Innovation Project of the Chinese Academy of Sciences (KZCX2-YW-BR-22).

\section{REFERENCES}

Bradley, R.S., F.T. Keimig and H.F. Diaz. 2004. Projected temperature changes along the American cordillera and the planned GCOS network. Geophys. Res. Lett., 31(16), L16210. (10.1029/2004GL020229.)

Collins, W.G. 2001. The operational complex quality control of radiosonde heights and temperatures at the National Centers for Environmental Prediction. Part I: description of the method. J. Appl. Meteorol., 40(2), 137-151.

Coudrain, A., B. Francou and Z.W. Kundzewicz. 2005. Glacier shrinkage in the Andes and consequences for water resources editorial. Hydrol. Sci. J., 50(6), 925-932.

Diaz, H.F. and N.E. Graham. 1996. Recent changes in tropical freezing heights and the role of sea surface temperature. Nature, 383(6596), 152-155.

Diaz, H.F., J.K. Eischeid, C. Duncan and R.S. Bradley. 2003. Variability of freezing levels, melting season indicators, and snow cover for selected high-elevation and continental regions in the last 50 years. Climatic Change, 59(1-2), 33-52.

Easterling, D.R. and T.C. Peterson. 1995. A new method for detecting undocumented discontinuities in climatological time series. Int. J. Climatol., 15(4), 369-377.

Favier, V., P. Wagnon, J.P. Chazarin, L. Maisincho and A. Coudrain. 2004. One-year measurements of surface heat budget on the ablation zone of Antizana Glacier 15, Ecuadorian Andes. J. Geophys. Res., 109(D18), D18105. (10.1029/2003JD004359.)

Folland, C.K. and 9 others. 2001. Observed climate variability and change. In Houghton, J.T. and 7 others, eds. Climate change 2001: the scientific basis. Contribution of Working Group I to the Third Assessment Report of the Intergovernmental Panel on Climate Change. Cambridge, etc., Cambridge University Press, 99-181.

Francou, B., M. Vuille, V. Favier and B. Cáceres. 2004. New evidence for an ENSO impact on low-latitude glaciers: Antizana 15, Andes of Ecuador, $0^{\circ} 28^{\prime}$ S. J. Geophys. Res., 109(D18), D18106. (10.1029/2003JD004484.)

Gaffen, D.J., B.D. Santer, J.S. Boyle, J.R. Christy, N.E. Graham and R.J. Ross. 2000. Multidecadal changes in the vertical temperature structure of the tropical troposphere. Science, 287(5456), $1242-1245$.

Guo, Y. and Y. Ding. 2009. Long-term free-atmosphere temperature trends in China derived from homogenized in situ radiosonde temperature series. J. Climate, 22(4), 1037-1051.

Guo, Y. and 6 others. 2008. Radiosonde temperature trends and their uncertainties over eastern China. Int. J. Climatol., 28(10), 1269-1281.

Harris, G.N., K.P. Bowman and D.-B. Shin. 2000. Comparison of freezing-level altitudes from the NCEP reanalysis with TRMM precipitation radar brightband data. J. Climate, 13(23), 4137-4148.

Hoffmann, G. 2003. Taking the pulse of the tropical water cycle. Science, 301(5634), 776-777.

Li, X., G. Cheng, Q. Wu and Y. Ding. 2003. Modeling Chinese cryospheric change by using GIS technology. Cold Reg. Sci. Technol., 36(1-3), 1-9.

Li, X. and 9 others. 2008. Cryospheric change in China. Global Planet. Change, 62(3-4), 210-218.

Ma, L., T. Zhang, Q. Li, O.W. Frauenfeld and D. Qin. 2008. Evaluation of ERA-40, NCEP-1, and NCEP-2 reanalysis air temperatures with ground-based measurements in China. J. Geophys. Res., 113(D15), D15115. (10.1029/ 2007JD009549.)

Solomon, S. and 7 others, eds. 2007. Climate change 2007: the physical science basis. Contribution of Working Group I to the Fourth Assessment Report of the Intergovernmental Panel on Climate Change. Cambridge, etc., Cambridge University Press.

Tang, G.L. and G.Y. Ren. 2005. Reanalysis of surface air temperature change of the last 100 years over China. Clim. Environ. Res., 10(4), 791-798. [In Chinese.]

Vergara, W. and 7 others. 2007. Economic impacts of rapid glacier retreat in the Andes. Eos, 88(25), 261. 
Vuille, M. and 6 others. 2008. Climate change and tropical Andean glaciers: past, present and future. Earth-Sci. Rev., 89(3-4), 79-96.

Wagnon, P., P. Ribstein, B. Francou and J.E. Sicart. 2001. Anomalous heat and mass budget of Glaciar Zongo, Bolivia, during the 1997/98 El Niño year. J. Glaciol., 47(156), 21-28.

World Glacier Monitoring Service (WGMS). 2008. Global glacier changes: facts and figures, ed. M. Zemp, I. Roer, A. Kääb, M. Hoelzle, F. Paul and W. Haeberli. Geneva, World Glacier Monitoring Service/United Nations Environment Programme.
Wu, Q. and T. Zhang. 2010. Changes in active layer thickness over the Qinghai-Tibetan Plateau from 1995 to 2007. J. Geophys. Res., 115(D9), D09107. (10.1029/2009JD012974.)

Yang, H., Z. Li, B. Ye, K. Jiao and Z. Zhao. 2005. Study on mass balance and process of Glacier No. 1 at the headwaters of the Ürümqi River in the past 44 years. Arid Land Geogr., 28(1), 76-80. [In Chinese with English summary.]

Zhang, Y., K. Fujita, Y. Ageta, M. Nakawo, T. Yao and J. Pu. 1998. The response of glacier ELA to climate fluctuations on HighAsia. Bull. Glacier Res., 16, 1-11. 